\title{
Trends in Obesity and Abdominal Obesity in the Older Adult Population of Spain (2000-2010)
}

\author{
Juan Luis Gutiérrez-Fisac ${ }^{a}$ b Luz M. León-Muñoz ${ }^{a, b} \quad$ Enrique Regidor ${ }^{b}$ c \\ JoséR. Banegas ${ }^{\mathrm{a}, \mathrm{b}}$ Fernando Rodríguez-Artalejo ${ }^{\mathrm{a}, \mathrm{b}}$ \\ ${ }^{a}$ Department of Preventive Medicine and Public Health, School of Medicine, Universidad \\ Autónoma de Madrid/IdiPAZ - CIBER in Epidemiology and Public Health (CIBERESP), \\ ${ }^{b}$ CIBER in Epidemiology and Public Health (CIBERESP), ${ }^{c}$ Department of Preventive Medicine \\ and Public Health, School of Medicine, Universidad Complutense de Madrid, Madrid, Spain
}

\author{
Key Words \\ Obesity $\cdot$ Abdominal obesity $\cdot$ Prevalence $\cdot$ Elderly $\cdot$ Spain
}

\begin{abstract}
Objective: This work examines the trend in obesity and abdominal obesity in the Spanish population aged 60 years and over during the first decade of the 21st century. Methods: We analyze data from a representative study of the Spanish population aged 60 years and older conducted in 2000-2001 and from the Study on Nutrition and Cardiovascular Risk in Spain (ENRICA) conducted in 2008-2010. Results: In men, the distribution of BMI did not vary in the period 2000-2010. In contrast, in women there was a reduction in both mean BMI - from 29.3 to $28.8 \mathrm{~kg} / \mathrm{m}^{2}$ - and the prevalence of obesity - from 40.8 to $36.3 \%$. This decline was greatest in women aged 60-69 years. In men, no significant changes were observed in mean waist circumference (WC) or in the prevalence of abdominal obesity. In contrast, WC decreased by 3.6 $\mathrm{cm}$ and abdominal obesity prevalence by $12.7 \%$ in women. The decline was greatest in women aged 60-69 years, in whom mean WC decreased by $5.1 \mathrm{~cm}$ and abdominal obesity prevalence by $18.6 \%$. Conclusion: These findings show that the frequency of obesity has begun to decline in Spanish women aged 60 and over. The causes of this decline are unclear.
\end{abstract}

Copyright (c) 2013 S. Karger GmbH, Freiburg

\section{Introduction}

The main epidemiological characteristic of obesity is its rising trend in much of the world over the last 20 or more years [1,2]. Although most studies of the obesity epidemic have focused on children and middle-aged adults, some studies have also shown increased obesity 
Gutiérrez-Fisac et al.: Trends in Obesity and Abdominal Obesity in the Older Adult Population of Spain (2000-2010)

in older adults. In the USA, the percentage of men aged 60 years and older with a BMI $\geq 30$ $\mathrm{kg} / \mathrm{m}^{2}$ increased between 1999and 2000 as well as between 2007 and 2008, but there was no significant trend among women [3]. In Canada, the prevalence of obesity showed an absolute increase of 7\% in women and 10\% in men aged 55-74 years between 1986-1992 and 2004 [4]. This upward trend in obesity in older adults has also been seen in some European countries like England [5], Finland [6], and Sweden [7], and even in some Asian populations [8].

The effect of BMI on mortality in the elderly is controversial. Whereas some studies show that BMI is associated with higher mortality, others have found the opposite [9]. However, some of these studies suggest that abdominal obesity, as estimated by waist circumference (WC) independently of BMI, is a powerful predictor of cardiovascular risk [10] and death from all causes in older adults $[11,12]$. This may be due to changes in body composition with advancing age so that BMI in the elderly reflects not only fat mass but also lean mass, with beneficial effects on mortality. Therefore, it is important to take abdominal obesity as well as general obesity into account.

Some studies indicate that central obesity is also increasing in the older adult population. In the USA the prevalence of abdominal obesity in subjects aged 60 years and older increased between 1988-1994 and 2003-2004 in men and, to a lesser degree, in women [13]. In the Canadian population aged 60-69 years, the mean WC increased from 87.9 to $98.1 \mathrm{~cm}$ and the prevalence of abdominal obesity rose from 21.3 to $56.6 \%$ between 1981 and 2007-2009 [14]. Similar trends in abdominal obesity have been observed in older adults in England [5, 15], Sweden [7], and Portugal [16].

To date, obesity trends in Spain have been studied using data on self-reported weight and height [17]; furthermore, data on the trend in abdominal obesity were not available. However, the Study on Nutrition and Cardiovascular Risk in Spain (ENRICA) conducted in $2008-2010[18,19]$ has made it possible to compare the frequency of obesity and abdominal obesity with that obtained in a study of the Spanish population aged 60 years and older in 2000-2001 [20].

\section{Participants and Methods}

The data analyzed herein were taken from two studies conducted in 2000-2001 and 2008-2010. The first study was carried out in a representative sample of the non-institutionalized population aged $\geq 60$ years in Spain. The data were collected between October 2000 and February 2001. The study methods have been reported elsewhere [20]. Briefly, study subjects were selected through probabilistic multistage cluster sampling. Census sections were selected at random in each cluster, followed by individual households where information was then obtained from residents. A total of 4,009 subjects ( $71 \%$ of those invited) participated. The information was collected through personal interview using a structured questionnaire, followed by a physical examination. The study was approved by the Clinical Research Ethics Committee of the 'La Paz' University Teaching Hospital, and written informed consent was obtained from all participants.

The ENRICA study was conducted between June 2008 and October 2010 in a representative sample of the Spanish population aged 18 years and older. The information was collected by trained personnel in participants' homes in three sequential stages: i) computer-assisted telephone interview, ii) first home visit to obtain biological samples (blood and urine), and iii) second home visit to measure anthropometric variables and blood pressureas well as to take a dietary history. The study methods have been reported elsewhere [18]. Briefly, the study participants were selected by stratified cluster sampling. The sample was first stratified by province and size of municipality. Second, clusters were selected randomly in two stages: municipalities and census sections. Finally, the households within each section were selected by random telephone dialing using the directory of fixed telephone lines as the sampling frame. Subjects in the households were selected proportionally to the distribution of the population of Spain by sex and age. Of the 22,387 subjects who were invited to participate in the study, 12,985 (58\%) responded to the telephone interview. Of these, $12,880(99.2 \%)$ provided a sample of blood and urine, and 11,191 (86.9\%) participated in the physical exam- 
Gutiérrez-Fisac et al.: Trends in Obesity and Abdominal Obesity in the Older Adult Population of Spain (2000-2010)

ination and provided dietary information. In this study we use data from the 3,488 individuals aged $\geq 60$ years. The study protocol was approved by the Clinical Research Ethics Committees of the University Teaching Hospital 'La Paz' in Madrid and of the Hospital 'Clinic' in Barcelona.

In both studies the anthropometry, including weight, height, and WC, was performed by trained interviewers using standardized techniques and equipment [21]. Body weight was measured to the nearest 0.1 kg using a calibrated electronic scale (Seca Models 812 and 841; Vogel \& Halke, Hamburg, Germany), with the subject barefoot and dressed in lightweight clothing. Height was measured barefoot to the nearest $0.1 \mathrm{~cm}$ using a portable extendable stadiometer (KaWe, Asperg, Germany). WC was measured with a flexible belttype tape on persons wearing lightweight clothing. Anthropometry was performed in 89.4 (weight and height) and $91.8 \%$ (WC) of the study participants in 2000-2001 and in 93.1 and $93.8 \%$ of the participants aged $\geq 60$ years in $2008-2010$.

BMI was calculated as the weight in kilogram divided by square of the height in meter. We obtained the mean BMI and WC and the prevalence of obesity (BMI $\geq 30 \mathrm{~kg} / \mathrm{m}^{2}$ ) and abdominal obesity (WC $>102 \mathrm{~cm}$ in men and WC $>88 \mathrm{~cm}$ in women) by sex and age groups. We calculated absolute differences (and their 95\% confidence intervals (95\% CI)) for BMI, WC and prevalence of obesity and abdominal obesity between 20082010 and 2000-2001. Data were analyzed using the survey procedures in STATA (v.11.1: Science Plus Group, Groningen, the Netherlands); the analysis took into account the sampling design, thereby ensuring that the results would represent population estimates.

\section{Results}

Figure 1a shows no substantive changes in the distribution of BMI in men in the period 2000-2010. Although mean BMI increased slightly, there were no statistically significant changes in mean BMI or in obesity prevalence in any age group (table 1). In contrast, figure $1 \mathrm{~b}$ shows a leftward shift in the distribution of BMI in women in 2000-2010, which indicates a reduction in mean BMI and prevalence of obesity. As seen in table 1, mean BMI in women declined from 29.3 to $28.8 \mathrm{~kg} / \mathrm{m}^{2}$, and the prevalence of obesity dropped from 40.8 to $36.3 \%$. However, this trend varied with age: Whereas in women aged 60-69 years mean BMI decreased by $1.4 \mathrm{~kg} / \mathrm{m}^{2}$ and the prevalence of obesity by $11.5 \%$, in those aged 80 years and older mean BMI increased by $0.5 \mathrm{~kg} / \mathrm{m}^{2}$ and the prevalence of obesity by $2.4 \%$, although the latter result was not statistically significant.

The trends in WC and abdominal obesity in each sex were consistent with those for BMI and obesity. Figure 1c shows a similar distribution of WC in men in 2000-2001 and 20082010. Significant changes were observed in mean WC or abdominal obesity prevalence neither in men overall nor in those aged 60-79 years. However, WC and abdominal obesity prevalence increased in men aged 80 years and older (table 2). In contrast, figure $1 \mathrm{~d}$ shows a shift to the left in the distribution of WC in women, which suggests a decrease in mean WC and abdominal obesity prevalence. Specifically, mean WC declined by $3.6 \mathrm{~cm}$ and abdominal obesity prevalence by $12.7 \%$. The reduction was observed in all age groups, although it was greatest in women aged 60-69 years in whom mean WC declined by $5.1 \mathrm{~cm}$ and abdominal obesity prevalence by $18.6 \%$ (table 2 ).

\section{Discussion}

In the Spanish population aged 60 or older, the frequency of obesity and abdominal obesity stabilized in men and declined considerably in women in the period 2000-2010.

Two previous studies have shown a reduced frequency of obesity in older women. The first showed that obesity prevalence in women aged 60 years and older in the USA declined slightly between 2000 and 2008 [3]. In the second study which was conducted in Gothenburg 
Gutiérrez-Fisac et al.: Trends in Obesity and Abdominal Obesity in the Older Adult Population of Spain (2000-2010)
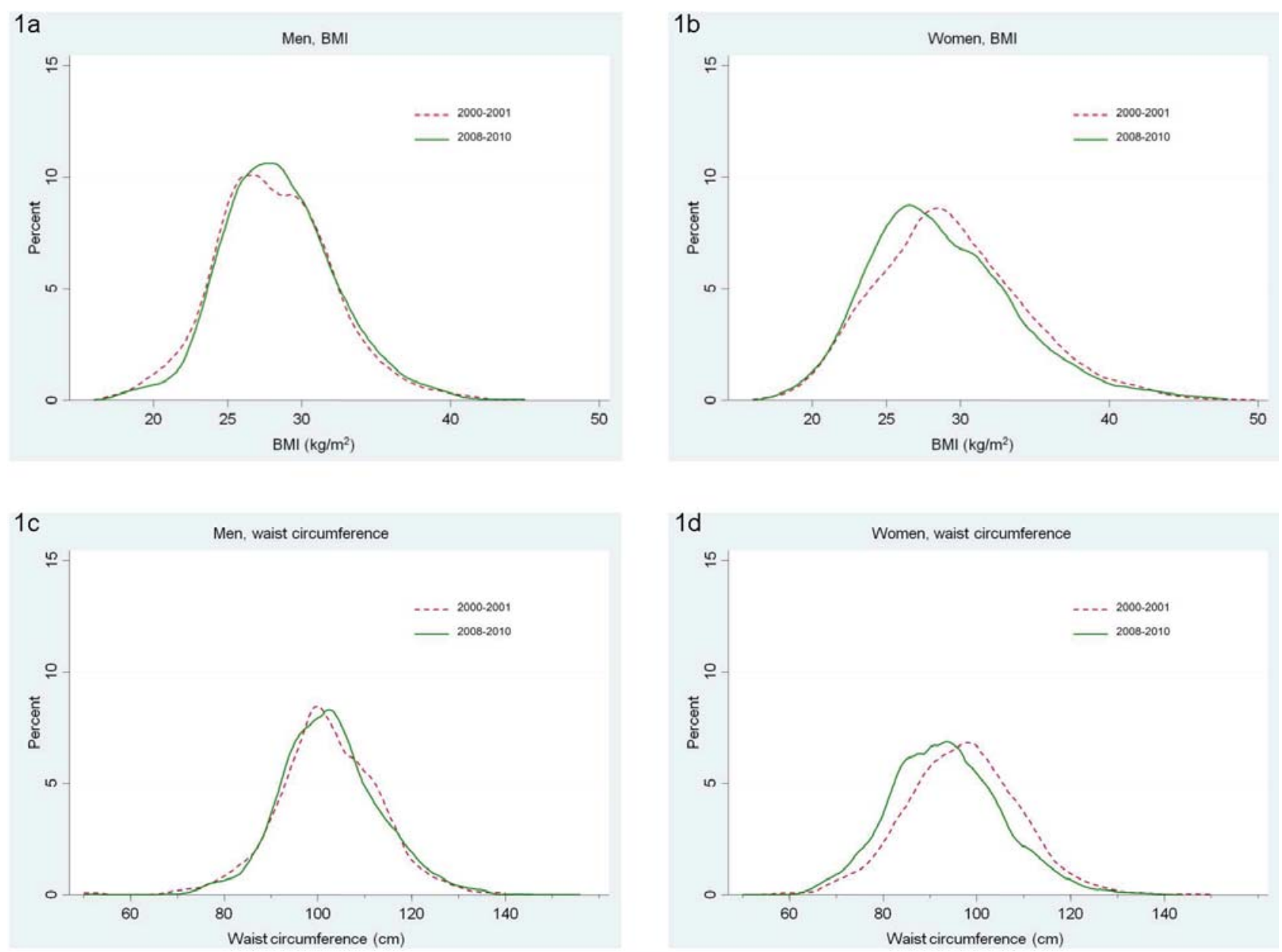

Fig. 1. Changes in the distribution of BMI and WC between 2000 and 2001 as well as 2008 and 2010 in Spanish men and women aged 60 years or older.

(Sweden), the prevalence of abdominal obesity decreased in women aged 55-64 years between 1986 and 2004 [22]. However, most studies in older adults, including those in the USA [13, 23], Canada [4, 14], England [5, 15], Portugal [16], Finland [6], Sweden [7] and Korea [8], have shown an increase in general and abdominal obesity in both men and women.

Two facts support the conclusion that the decreased obesity rate in Spanish women aged 60 and older in the last decade is real. First, as shown in figure 1, the decline has affected both $\mathrm{BMI}$ and $\mathrm{WC}$, and has occurred throughout the entire distribution and not only at the beginning and end. Second, these results are consistent with those of health interview surveys in Spain, which have shown a steady increase in overweight and obesity between 1987 and 2007 in men aged 65 years and older, and a decrease, beginning in 2001, in women in this age group [17].

Another fact supporting our results is that obesity prevalence in the adult population of several countries has increased more in men than in women. In the US population aged 20 years and older, obesity prevalence increased by $17 \%$ in men and by $6 \%$ in women between 1999 and 2008 [3], and abdominal obesity prevalence increased by $9.6 \%$ in men and $8.4 \%$ in women between 1994 and 2000 [23]. This greater impact in men has also been seen in adults in England [5], Canada [4], and Sweden [24, 25]. In older adults, obesity has also increased 
Gutiérrez-Fisac et al.: Trends in Obesity and Abdominal Obesity in the Older Adult Population of Spain (2000-2010)

Table 1. BMI and prevalence (\%) of obesity (BMI $\geq 30 \mathrm{~kg} / \mathrm{m}^{2}$ ) in Spanish men and women aged 60 years or older in 2000-2001 and 2008-2010

\begin{tabular}{|c|c|c|c|c|c|c|c|c|}
\hline \multirow[t]{3}{*}{ Age group } & \multicolumn{2}{|l|}{$\mathrm{n}$} & \multicolumn{3}{|c|}{ BMI, $\mathrm{kg} / \mathrm{m}^{2}$} & \multicolumn{3}{|c|}{ Prevalence of obesity, \% } \\
\hline & \multirow{2}{*}{$\begin{array}{l}2000- \\
2001\end{array}$} & \multirow{2}{*}{$\begin{array}{l}2008- \\
2010\end{array}$} & \multicolumn{2}{|l|}{ mean } & \multirow{2}{*}{$\begin{array}{l}\text { BMI mean } \\
\text { difference }^{\dagger} \\
(95 \% \text { CI })\end{array}$} & \multicolumn{2}{|c|}{ prevalence } & \multirow{2}{*}{$\begin{array}{l}\text { prevalence } \\
\text { difference } \\
(95 \% \mathrm{CI})\end{array}$} \\
\hline & & & $\begin{array}{l}2000- \\
2001\end{array}$ & $\begin{array}{l}2008- \\
2010\end{array}$ & & $\begin{array}{l}2000- \\
2001\end{array}$ & $\begin{array}{l}2008- \\
2010\end{array}$ & \\
\hline Men & 1,571 & 1,479 & 28.2 & 28.5 & $0.3(-0.02 ; 0.62)$ & 31.5 & 31.4 & $-0.1(-4.11 ; 3.91)$ \\
\hline $60-69$ years & 773 & 904 & 28.5 & 28.7 & $0.2(-0.24 ; 0.64)$ & 35.0 & 31.9 & $-3.1(-8.79 ; 2.59)$ \\
\hline $70-79$ years & 578 & 456 & 28.2 & 28.2 & $0.0(-0.57 ; 0.57)$ & 31.4 & 31.3 & $-0.1(-6.74 ; 6.54)$ \\
\hline$\geq 80$ years & 220 & 120 & 26.9 & 27.6 & $0.7(-0.24 ; 1.64)$ & 19.4 & 28.2 & $8.8(-2.39 ; 19.99)$ \\
\hline Women & 1,965 & 1,765 & 29.3 & 28.8 & $-0.5(-0.88 ;-0.12)$ & 40.8 & 36.3 & $-4.5(-8.14 ;-0.86)$ \\
\hline $60-69$ years & 824 & 959 & 29.9 & 28.5 & $-1.4(-1.90 ;-0.90)$ & 43.8 & 32.3 & $-11.5(-16.63 ;-6.37)$ \\
\hline $70-79$ years & 733 & 661 & 29.7 & 29.5 & $-0.2(-0.74 ; 0.34)$ & 44.0 & 43 & $-1.0(-7.07 ; 5.07)$ \\
\hline$\geq 80$ years & 408 & 145 & 27.5 & 28.0 & $0.5(-0.61 ; 1.61)$ & 29.2 & 31.6 & $2.4(-7.79 ; 12.59)$ \\
\hline
\end{tabular}

${ }^{\dagger}$ Mean 2008-2010 minus mean 2000-2001.

‡ Prevalence 2008-2010 minus prevalence 2000-2001.

Table 2. WC and prevalence (\%) of abdominal obesity in Spanish men and women aged 60 years or older in $2000-2001$ and $2008-2010$

\begin{tabular}{|c|c|c|c|c|c|c|c|c|}
\hline \multirow[t]{3}{*}{ Age group } & \multicolumn{2}{|l|}{$\mathrm{n}$} & \multicolumn{3}{|l|}{$\mathrm{WC}, \mathrm{cm}$} & \multicolumn{3}{|c|}{ Prevalence of obesity, \% } \\
\hline & \multirow{2}{*}{$\begin{array}{l}2000- \\
2001\end{array}$} & \multirow{2}{*}{$\begin{array}{l}2008- \\
2010\end{array}$} & \multicolumn{2}{|l|}{ mean } & \multirow{2}{*}{$\begin{array}{l}\text { WC mean } \\
\text { difference }^{\dagger} \\
(95 \% \mathrm{CI})\end{array}$} & \multicolumn{2}{|c|}{ prevalence } & \multirow{2}{*}{$\begin{array}{l}\text { prevalence } \\
\text { difference } \\
(95 \% \mathrm{CI})\end{array}$} \\
\hline & & & $\begin{array}{l}2000- \\
2001\end{array}$ & $\begin{array}{l}2008- \\
2010\end{array}$ & & $\begin{array}{l}2000- \\
2001\end{array}$ & $\begin{array}{l}2008- \\
2010\end{array}$ & \\
\hline Men & 1,600 & 1,492 & 102.2 & 102.6 & $0.4(-0.50 ; 1.30)$ & 48.4 & 50.2 & $1.8(-2.43 ; 6.03)$ \\
\hline $60-69$ years & 780 & 912 & 102.8 & 102.3 & $-0.5(-1.69 ; 0.69)$ & 50.1 & 49.2 & $-0.9(-6.70 ; 4.90))$ \\
\hline $70-79$ years & 592 & 458 & 102.6 & 103.0 & $0.4(-1.19 ; 1.99)$ & 49.5 & 52.5 & $3.0(-4.24 ; 10.24)$ \\
\hline$\geq 80$ years & 228 & 122 & 99.4 & 102.6 & $3.2(0.61 ; 5.79)$ & 39.6 & 48.9 & $9.3(-3.46 ; 22.06)$ \\
\hline Women & 2,042 & 1,781 & 97.1 & 93.5 & $-3.6(-4.47 ;-2.73)$ & 78.4 & 65.7 & $-12.7(-16.18 ;-9.22)$ \\
\hline $60-69$ years & 863 & 969 & 97.1 & 92.0 & $-5.1(-6.26 ;-3.94)$ & 78.5 & 59.9 & $-18.6(-23.45 ;-13.75)$ \\
\hline $70-79$ years & 754 & 667 & 98.0 & 95.6 & $-2.4(-3.78 ;-1.02)$ & 81.8 & 73.3 & $-8.5(-13.28 ;-3.72)$ \\
\hline$\geq 80$ years & 425 & 145 & 95.4 & 93.5 & $-1.9(-4.29 ; 0.49)$ & 72.1 & 69.6 & $-2.5(-12.41 ; 7.41)$ \\
\hline
\end{tabular}

${ }^{\dagger}$ Mean 2008-2010 minus mean 2000-2001.

‡ Prevalence 2008-2010 minus prevalence 2000-2001.

more in men. Thus, from 2000 to 2008 in the USA, the prevalence of obesity increased by $17 \%$ in men aged 60 years and older, whereas it declined slightly in women of the same age [3]; abdominal obesity prevalence also increased more in men than in women over 60 years of age [23]. In Gothenburg, general obesity in subjects aged 70 years and older increased more in men than in women [22]. Similar results have been found in the Finnish population aged 60-64 years [26] and in persons aged 55 years and older in England [5] and in Canada [4]. 
Gutiérrez-Fisac et al.: Trends in Obesity and Abdominal Obesity in the Older Adult Population of Spain (2000-2010)

This all suggests that certain obesogenic factors are affecting men more than women and may be modifying the obesity trend in women.

Several factors may explain gender differences in the obesity trend in older adults in Spain. The first factor is physical activity and sedentary lifestyles, which have a well-established association with obesity at both the individual and the population level [27]. During the study period, the time spent sitting, reading, or watching television decreased more in women (from $33.8 \mathrm{~h} /$ week in 2000 to $23.3 \mathrm{~h} /$ week in 2010) than in men (from 32.9 to 31.1 $\mathrm{h}$ /week). Furthermore, the percentage of the population who reported being sedentary in their main activity decreased much more in women (from $22.2 \%$ in 2000 to $11.8 \%$ in 2010) than in men (from 22.1 to 17.1\%). In addition, national health interview surveys in Spain show that the percentage of the population aged 65 years and older who engaged in any moderate or intense physical activity increased much more in women than in men [28]. All of these data indicate that women have more increased energy expenditure than men in the last few years. The reasons for the reduction in sedentary behavior and physical inactivity in women are not completely understood, but a greater role of women in professional and social tasks in Spain during the past three decades may have contributed to the observed gender differences in physical activity trends.

Smoking is another factor that could contribute to gender differences in the obesity trend $[29,30]$. In Spain, the smoking epidemic has lagged behind that of other western countries, and while smoking in men is on the decline, it continues to increase in women in some age groups. Thus, in men aged 60 years and older, smoking prevalence dropped from $20.7 \%$ in 2000 to $18.8 \%$ in 2010 , but it increased in women in this age group from 2 to $6.4 \%$. The increase in smoking in women was highest in those aged 60-69 years, the same group that showed the greatest decline in obesity. However, given the low prevalence of smoking in older women, this would have only a modest effect on obesity.

There is some evidence that changes in the consumption of certain foods, including increased fruit and vegetable intake, are associated with less lifetime weight gain [31]. Although the ENRICA study collects information on food consumption, the study conducted in 2000-2001 did not make an exhaustive measure of dietary variables; therefore, it is not possible to analyze their contribution to trends in obesity. The only information available comes from the Spanish health interview surveys, which show that in the study period there was an increase in the proportion of the population aged 55 years and older who consume fruits and vegetables daily, and that this increase was similar in men and women [28]. Thus, the impact of diet on the decreased obesity prevalence in Spanish women is unknown, but it is likely to be of less importance than physical activity, which is probably the main explanation for the decrease in the obesity prevalence observed in women.

Finally, selective survival may also have contributed to our findings. In Spain, morbid obesity is more frequent in women than in men [32]. Thus, given that morbid obesity is associated with higher mortality than lesser levels of obesity, the prevalence of obesity in women could have declined due to higher mortality in obese women. In fact, obesity as a certified cause of death (ICD-10 code E66) is increasing in Spain, rising from 260 certified deaths in 1999 to 754 in 2009. Although the increase was similar in both sexes, the number of deaths was considerably higher in women than in men throughout the period. Specifically, in 2009 there were 216 and 538 deaths in men and women, respectively, of which $60 \%$ and $85 \%$ were persons aged 60 years and older in men and women, respectively [33].

The present study has two main strengths. The first one is the large sample size of both study groups as well as its representativeness so that the results can be generalized to the entire country. The second strength is the use of objective measures of weight, height, and WC. One possible limitation is that the response rate in the ENRICA study was 51\%. This rate is somewhat lower than that in the NHANES III carried out in 2007-2008 in the USA [34], but 
Gutiérrez-Fisac et al.: Trends in Obesity and Abdominal Obesity in the Older Adult Population of Spain (2000-2010)

it is among the highest of the health interview and examinations surveys conducted in Europe [35]. Moreover, the observed sex, age, and educational level structure of the ENRICA study closely resemble the sociodemographic distribution of the Spanish population in 2009 [18]. Thus, both the response rate and the sample structure suggest that the ENRICA study is representative of the adult population of Spain.

In conclusion, this study shows that the frequency of obesity has begun to decline in Spanish women aged 60 years and older. This decline has been seen in some other adult populations in various countries [36], but future studies are needed to determine if it will continue over time. It is not clear why obesity is declining in women nor do we have sufficient understanding of the drivers of the obesity epidemic in a large part of the world [27]. However, important lifestyle changes have occurred among Spanish women in the last few decades, in particular with respect to physical activity which results from a more active social role of women, and it is likely that they have contributed to the declining prevalence of obesity.

\section{Acknowledgement}

This work has been supported by FIS grant PI09-1626 and by 'Cátedra UAM de Epidemiología y Control del Riesgo Cardiovascular'.

\section{Disclosure Statement}

The authors declare no conflict of interest.

\section{References}

1 Finucane MM, Stevens GA, Cowan MJ, Danaei G, Lin JK, Paciorek CJ, et al; Global Burden of Metabolic Risk Factors of Chronic Diseases Collaborating Group (Body Mass Index): National, regional, and global trends in body-mass index since 1980: systematic analysis of health examination surveys and epidemiological studies with 960 country-years and 9.1 million participants. Lancet 2011;377:557-567.

2 IASO: Publications: Obesity Data Portal. www.iaso.org/resources/obesity-data-portal// (accessed January, 30, 2013).

3 Flegal KM, Carroll MD, Ogden CL, Curtin LR: Prevalence and trends in obesity among US adults, 1999-2008. JAMA 2010;303:235-241.

- 4 Shields M, Tjepkema M: Trends in adult obesity. Health Rep 2006;17:53-59.

5 National Health Service, The Information Centre for Health and Social Care: Statistics on obesity, physical activity and diet. www.ic.nhs.uk/statistics-and-data-collections/health-and-lifestyles/obesity/statistics-onobesity-physical-activity-and-diet-england-2011 (accessed January 30, 2013).

- 6 Lahti-Koski M, Seppänen-Nuijten E, Männistö S, Härkänen T, Rissanen H, Knekt P, Rissanen A, Heliövara M: Twenty-year changes in the prevalence of obesity among Finnish adults. Obes Rev 2010;11:171-176.

7 Lilja M, Eliasson M, Stegmayr B, Olsson T, Söderberg S: Trends in obesity and its distribution: data from the Northern Sweden MONICA Survey, 1986-2004. Obesity (Silver Spring) 2008;16:1120-1128.

- 8 Khang YH, Yun SC: Trends in general and abdominal obesity among Korean adults: findings from 1998, 2001, 2005 and 2007 Korea National Health and Nutrition Examination Surveys. J Korean Med Sci 2010;25:15821588.

9 Janssen I, Mark AE: Elevated boby mass index and mortality risk in the elderly. Obes Rev 2007;8:41-59.

10 Goodpaster BH, Krishnaswami S, Harris TB, et al: Obesity, regional body fat distribution, and the metabolic syndrome in older men and women. Arch Intern Med 2005;165:777-783.

11 Wannamethee SG, Shaper AG, Lennon L, Whincup PH: Decreased muscle mass and increased central adiposity are independently related to mortality in older men. Am J Clin Nutr 2007;86:1339-1346.

-12 Guallar-Castillón P, Balboa-Castillo T, López-García E, León-Muñón L, Gutiérrez-Fisac JL, Banegas JR, RodríguezArtalejo F: Obesity and mortality according to health status in the elderly: a 6-year prospective cohort study. Obesity (Silver Spring) 2009;17:2232-2238.

13 Li C, Ford ES, McGuire LC, Mokdad AH: Increasing trends in waist circumference and abdominal obesity among US adults. Obesity (Silver Spring) 2007;15:216-224. 
Gutiérrez-Fisac et al.: Trends in Obesity and Abdominal Obesity in the Older Adult Population of Spain (2000-2010)

14 Janssen I, Shields M, Craig CL, Tremblay MS. Prevalence and secular changes in abdominal obesity in Canadian adolescents and adults, 1981 to 2007-2009. Obes Rev 2011;12:397-405.

15 Howel D. Trends and prevalence of abdominal obesity and overweight in English adults (1993-2008). Obesity (Silver Spring) 2011 doi:10.1038/oby.2011.127.

16 Do Carmo I, dos Santos 0, Camolas J, Vieira J, Carreira M, Medina L, Reis L, Myatt J, Galvao-Teles A: Overweight and obesity in Portugal: national prevalence in 2003-2005. Obes Rev 2008;9:11-19.

17 Salcedo V, Gutiérrez-Fisac JL, Guallar-Castillón P, Rodríguez-Artalejo F: Trends in overweight and misperceived overweight in Spain from 1987 to 2007. Int J Obes (London) 2010;34:1759-1765.

-18 Rodríguez-Artalejo F, Graciani A, Guallar-Castillón P, León-Muñoz LM, Zuluaga MC, López-García E, GutiérrezFisac JL, Taboada JM, Aguilera MT, Regidor E, Villar-Álvarez F, Banegas JR: Rationale and methods of the Study on Nutrition and Cardiovascular Risk in Spain (ENRICA). Rev Esp Cardiol 2011;64:876-882.

19 Gutiérrez-Fisac JL, Guallar-Castillón P, León-Muñoz LM, Graciani A, Banegas JR, Rodríguez-Artalejo F: Prevalence of general and abdominal obesity in the adult population of Spain, 2008-2010:the ENRICA study. Obes Rev 2012;13:388-392.

20 Gutiérrez-Fisac JL, López E, Banegas JR, Graciani A, Rodríguez Artalejo F: Prevalence of overweight and obesity in elderly people in Spain. Obes Res 2004;12:710-715.

21 World Health Organization: Physical status: the use and interpretation of anthropometry. Report of a WHO Expert Committee. Technical Report Series, No. 854. Geneva, World Health Organization, 1995.

-22 Eiben G, Dey DK, Rothenberg E, Oteen B, Björkelund C, Bengtsson C, Lissner L: Obesity in 70-year-old Swedes: secular changes over 30 years. Int J Obes (London) 2005;29:810-817.

23 Ford ES, Mokdad AH, Giles WH: Trends in waist circumference among U.S. adults. Obes Res 2003;11:12231231.

24 Berg C, Rosengren A, Aires N, Lappas G, Torén K, Thelle D, Lissner L: Trends in overweight and obesity from 1985 to 2002 in Göteborg, West Sweden. Int J Obes (London) 2005;29:916-924.

25 Schneider H, Dietrich EV, Venetz WP: Trends and stabilization up to 2022 in overweight and obesity in Switzerland. Comparison to France, UK, US and Australia. Int J Environ Res Public Health 2010; 7:460-472.

-26 Lathi-Koski M, Jousilahti P, Pietinen P: Secular trends in body mass index by birth cohort in eastern Finland from 1972 to 1997. Int J Obes Relat Metab Disord 2001;25:727-734.

-27 Swinburn BA, Sacks G, Hall KD, McPherson K, Finegood DT, Moodie ML, Gortmaker SL: The global obesity pandemic: shaped by global drivers and local environments. Lancet 2011;378:804-814.

28 Ministerio de Sanidad, Servicios Sociales e Igualdad, Instituto de Información Sanitaria Portal Estadístico del SNS. www.msssi.gob.es/estadEstudios/estadisticas/sisInfSanSNS/aplicacionesConsulta/home.htm (last accessed January 30, 2013).

29 Rodu B, Stegmayr B, Nasic S, Cole P, Asplund K: The influence of smoking and smokeless tobacco use on weight amongst men. J Intern Med 2004;255:102-107.

-30 Flegal KM, Troiano RP, Pamuk ER, Kuczmarski RJ, Campbell SM: The influence of smoking cessation on the prevalence of overweight in the United States. N Engl J Med 1995;333:1165-1170.

-31 Mozaffarian D, Hao T, Rimm EB, Willett WC, Hu FB: Changes in diet and lifestyle and long-term weight gain in women and men. N Engl J Med 2011;364:2392-2404.

-32 Basterra-Gortari FJ, Beunza JJ, Bes-Rastrollo M, Toledo E, García-López M, Martínez-González MA: Increasing trend in the prevalence of morbid obesity in Spain: from 1.8 to 6.1 per thousand in 14 years. Rev Esp Cardiol 2011;64:424-426.

33 Instituto Nacional de Estadístca (INE): Defunciones según causa de muerte. www.ine.es/jaxi/tabla.do?path=/ $t 15 / p 417 / a 2009 / 10 / \&$ file=01000.px\&type $=p c a x i s \& L=0$. (last accessed January 30, 2013).

34 Centers for Disease Control and Prevention: National Health and Nutrition Examination Survey. NHANES Response Rates and CPS Totals. www.cdc.gov/nchs/nhanes/response_rates_CPS.htm (last accessed January 30, 2013).

35 Aromaa A, Koponen P, Tafforeau J, Vermeire C; HIS/HES Core Group: Evaluation of health interview surveys and health examination surveys in the European Union. Eur J Public Health 2003;13(3 suppl):67-72.

-36 Rokholm B, Baker JL, Sorensen TIA: The leveling off of the obesity epidemic since the year 1999 - a review of evidence and perspectives. Obes Rev 2010;11:835-846. 